\title{
Startups Support in Slovak Republic
}

\author{
Jarmila Hudáková \\ Constantine the Philosopher University in Nitra, Nitra, Slovakia
}

\begin{abstract}
In a knowledge-based society, innovation is the driving force of the economy on all levels and in all types of organizations. Due to high risks present when introducing new products and services, innovations are usually commercialized via isolated formal formations such as startup companies (next, just startup). The aim of the article is to empirically analyse the situation of startups in Slovakia and describe how Slovak republic supports startup. We used the questionnaire and we approached 289 small and medium enterprises, in case of which we assumed that they are startups. This assumption confirmed 153 startups based on the returned questionnaires. Slovak Republic has all that is necessary for the startup ecosystem. The survey showed that there is a need to support women in business and activate more investors interested in investments in startups. Founders of startup still use mainly own savings for funding business. Our findings can inspire new investors. Results may increase investors' interest in investing in startup companies due to the fact that the Slovak Republic conditions are created for this type of business.
\end{abstract}

Keywords: innovations, startup, the simplified joint stock company, ecosystem

\section{Introduction}

At the very beginning, let us define when a new company is considered to be a startup business. Blank (2010) says that start-ups do not form a small version of a large company and operate otherwise than classical small enterprises since their beginnings and internal operation is different. Thanedar (2012) distinguishes startups from small enterprises based on five criteria such as: profitability, long-term value, income, growth potential, and scalability.

However, no unified or generally valid definition of startup exists. It is possible to identify the common aspect though that is present in these definitions. Startups do not have to operate exclusively in the IT field and develop and apply high technology. Startups are established with the aim to create an innovative product or service. Innovation is their main competitive advantage. The unique context, in which startups begin, is characterised by novelty, small size, and uncertainty. Novelty according to Zäch and Bardegger (2017) in startups is shown mainly as a lack of experience of all employees. Small size is perceived as limited base of financial and human resources. According to Ries (2011), the above mentioned uncertainty involves, apart from uncertain success, also the heading of startups towards higher goals, which may not be realistic.

The growth criterion as crucial in start-up definition is emphasised by several authors. Damodaran (2009) states the value of startup consists exclusively in its future growth potential. Graham (2012) also emphasises

Jarmila Hudáková, Ph.D., MBA, assistant professor, Faculty of Natural Sciences, Institute of Economics and Management, Constantine the Philosopher University in Nitra, Nitra, Slovak Republic.

Correspondence concerning this article should be addressed to Jarmila Hudáková, Faculty of Natural Sciences, Institute of Economics and Management, Constantine the Philosopher University in Nitra, Tr. Andreja Hlinku 1, Nitra 94974, Slovak Republic. 
the growth criterion and designates a startup as an enterprise created for fast growth.

There are many opinions on what is and what is not a startup; these opinions differ from one another depending on the author of the definition, the country, and the purpose that the definition is created for.

Apart from the question that which newly established company is considered to be a start-up, it is necessary to handle the discrepancy of until when a startup may be considered to be a startup. According to Blank and Dorf (2012), the main goal of a startup is not further stay a startup but to succeed and become an organisation or on the contrary, not to succeed and seek other market opportunities. In the USA, there is a limit defined where the startup changes into a standard enterprise and it is as follows: turnover of USD 50 million for the last 12 months, number of employees 100 and more and the value of enterprise more than USD 500 million. However, under the circumstances of Slovakia, this criterion may not be applied. There are other criteria though, e.g., takeover by a bigger company (acquisition) or time criterion. The most commonly used border seems to be the expiration of three years as of the startup establishment.

Startups do not work as isolated firms but belong to the ecosystem (Figure 1). A startup ecosystem is formed by people, startups in their various stages, and various types of organizations in a location (physical and/or virtual), interacting as a system to create new startup companies. These organizations can be further divided into categories: universities, funding organizations, support organizations (like incubators, accelerators, co-working spaces etc.), research organizations, service provider organizations (like legal, financial services etc.), and large corporations. Different organizations typically focus on specific parts of the ecosystem function and/or startups at their specific development stage(s).

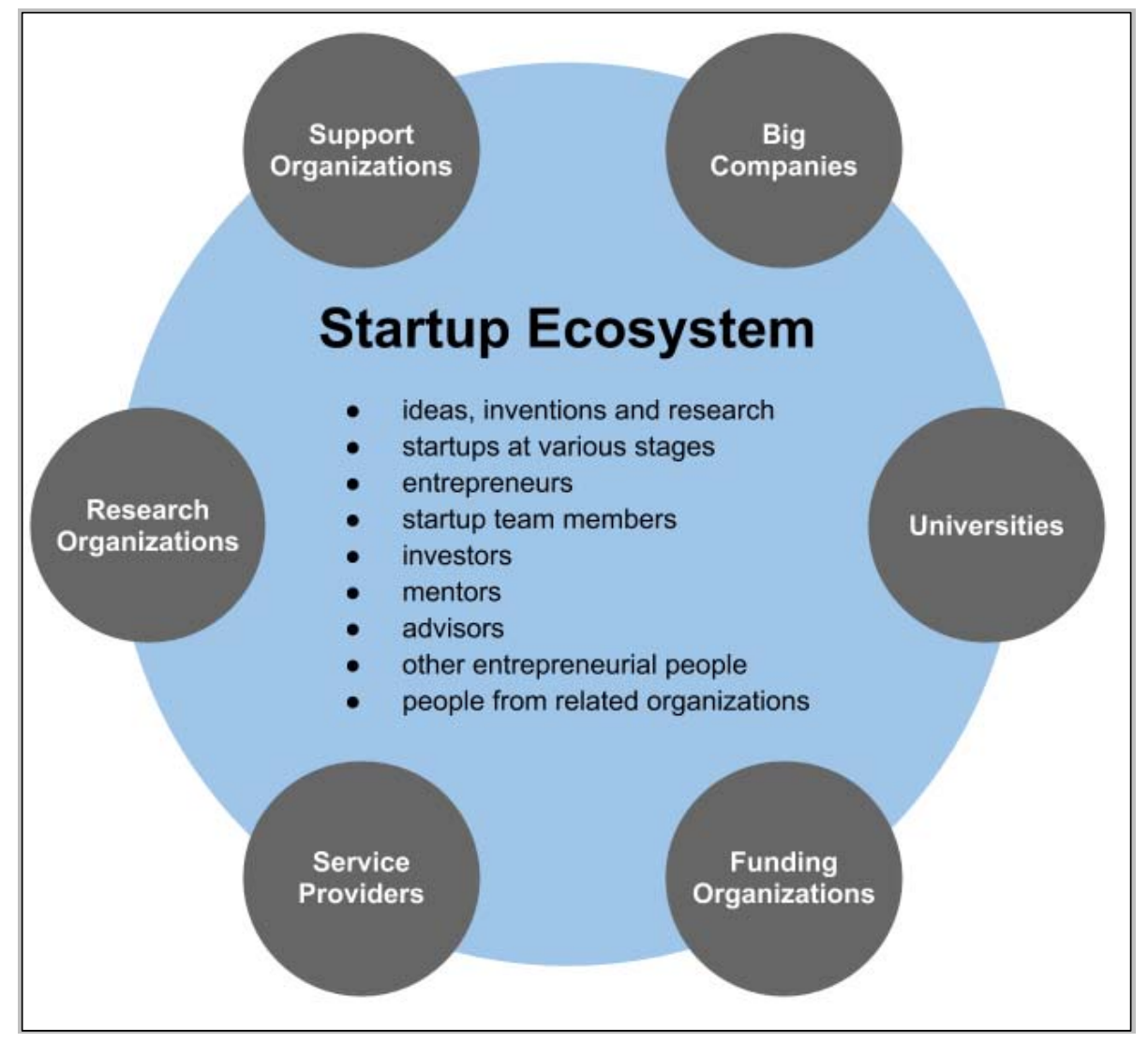

Figure 1. Startup ecosystem. Source: Startup Commons. 


\section{Research Methods}

In the first step, we analysed conditions for startups in Slovakia. The second step was to conduct research.

The basic set of surveyed enterprises was defined by:

- The basic condition was that the business is a startup;

- Territorial point of view - the company has its registered office in the Slovak Republic;

- Dimensional aspect — enterprises with fewer than 50 employees.

A quota selection method has been applied. Quoted variables have been selected as above variables. Two sources of information were used for the empirical survey:

- Publicly published information;

- Information from the crowdfunding webs

- Information from corporate websites

- Questionnaire survey information.

With respect to the fact that we were only interested in business that are startups their list, we have acquired from two Slovak crowdfunding sites: startitup and startupers. Using the questionnaire, we approached 289 small and medium enterprises, in case of which we assumed that they are startups. The questionnaire was distributed by mail. This assumption confirmed 153 startups based on the returned questionnaires. In the questionnaire we asked whether the founder is male or female, and what is his/her highest achieved education. Further we asked in which stage the startup is in, from what resources it is financed, and what are its priorities for the coming year.

\section{Research Results}

\section{Conditions for Startups in Slovak Republic}

The specifics of startups in comparison with traditional starting companies under the circumstances of the Slovak Republic according Hošták (2015) may be summarised as follows:

- The company was established for the purpose of creating an innovative product or service, and less than 36 months lapsed as of its establishment (time aspect does not have to be considered). Innovation is their main competitive advantage.

- It is a micro, small, or medium enterprise.

- It is characterised by that fact that the majority of voting rights belong to natural persons, who are their founders.

- After market entry fast growth is expected.

- A scalable business model is applied.

- It has international ambitions.

Business innovations can hinder external and internal barriers that slow down innovation activities or otherwise negatively affect them. These barriers can lead to the failure to start innovative projects to cancel them during implementation or to delay the introduction of innovations. In particular, there are barriers economic, market, knowledge, and other reasons not to invest (Klímová \& Winklerová, 2017).

Therefore the Ministry of Finance of the Slovak Republic (2015) drew up measures for supporting the business of beginning startups. The summary of startup support measures was as follows:

(1) Simplified joint stock company;

(2) Exemption from the obligation of tax licence payment; 
(3) Changes in making a security deposit upon voluntary VAT payer registration;

(4) Granting visas to start-ups from countries outside the EU (startup visas);

(5) Establishment of the National Business Centre;

(6) Creating a platform of angel investors;

(7) Provision of grant for students with innovative thinking prior to company establishment;

(8) Forming grant schemes for making the infrastructure of higher education institutions available to start-ups;

(9) Building the institutional capacity of higher education institutions for transfer of knowledge into practice;

(10) Support of quality education in the field of financial literacy at basic and secondary schools;

(11) Involvement in international programs stimulating cooperation of higher education institutions with the private sector;

(12) Creating a centre of excellence for information security;

(13) Regular meetings of the working group of the Visegrad Four in reference to the issue of start-ups and innovations;

(14) Creating a position for the permanent representative of the Slovak Republic from Silicon Valley;

(15) Incentives for angel investors;

(16) Improvement of capital financing for start-ups via the structure of Slovak Investment Holding;

(17) Introduction of new financial tools for start-ups within the National Business Centre;

(18) Improved support of start-ups and other small and medium enterprises in access to financing options in Europe.

The adopted amendment of Act No. 513/1991 Coll., Commercial Code, as amended as a whole deals only with one topic being the introduction of a new legal business form, namely a simplified joint stock company. The amendment of the Commercial Code came into force as of 1 January 2017 and since that date it is possible in Slovakia, apart from the four current business companies (public limited company, limited partnership, limited liability company, joint stock company), it is also possible to establish a fifth one-a simplified joint stock company. The new sixth head of the Commercial Code is devoted to it within the framework of business companies. Such a company may use after its business name the addendum "simplified joint stock company" or the abbreviation "j.a.s.". For violation of their liabilities, the simplified joint stock company will be liable with all its properties, but the shareholder will not be liable for the liabilities of the company at all.

The simplified joint stock company is a suitable form of business for beginning projects offering new or significantly innovated products, i.e., startups. The establishment of a simplified stock company is not limited in any way or tied to a startup project. It may be established even by any other entrepreneurs with any scope of business. The simplified joint stock company combines the features of a limited liability and joint stock company. From a limited liability company, for the founders of a simplified joint stock company, simple organisation structure and low-input capital is taken over. From the joint stock company, the advantages for investors (shareholders) are taken over into the simplified joint stock company, which enable them efficient entry, retention, and outcome from the investment. The relations of founders and investors may be regulated using different flexible institutes.

The simplified joint stock company may be established by one or more natural or legal persons. The value of minimum basic capital for a simplified joint stock company is EUR 1. The basic capital of the simplified joint 
stock company will be distributed to the actual number of shares with a certain nominal value. The nominal value of the share may be expressed in Euro cents or by combination of Euro and Euro cents. Prior to establishment of the company, the entire value of the basic capital must be subscribed and all capital contributions must be paid up. The condition for establishment of a simplified joint stock company is that it may not be established based on a public offer for the acquisition of shares, which means that its entire basic capital must be paid up by its founders upon establishment. Equally it is not possible to increase the basic capital of a simplified joint stock company based on a public offer for the acquisition of shares even during the course of its operation. A simplified joint stock company is not a public company.

The possibility to establish a simplified joint stock company has been available in Slovakia since 1 January 2017 and during this year, according to the Commercial Register, only 58 such companies were established. Table 1 shows the establishment and cancellation of all capital companies for the period from 2012 to 2017.

Table 1

Establishment and Cancellation of Capital Companies From 2012 to 2017

\begin{tabular}{lllllll}
\hline Capital companies & 2012 & 2013 & 2014 & 2015 & 2016 & 2017 \\
\hline Establishment & 21,112 & 28,764 & 14,953 & 13,807 & 19,466 & 2,1673 \\
Cancellation & 5,067 & 5,230 & 7,464 & 9,233 & 9,237 & 9,746 \\
Simple company on stock_establishment & - & - & - & - & - & 58 \\
\hline
\end{tabular}

Source: Commercial register of Slovak Republic.

Many beginning startups have visions and ideas. If a startup does not find a customer whose needs would satisfy and cannot make a profit, it no longer exists. Some of them, however, have achieved such a success that today they are considered renowned companies with top-notch and useful services or high-quality technological products. Figure 2 shows the 15 biggest companies in Slovakia according to revenues, which began as startup.

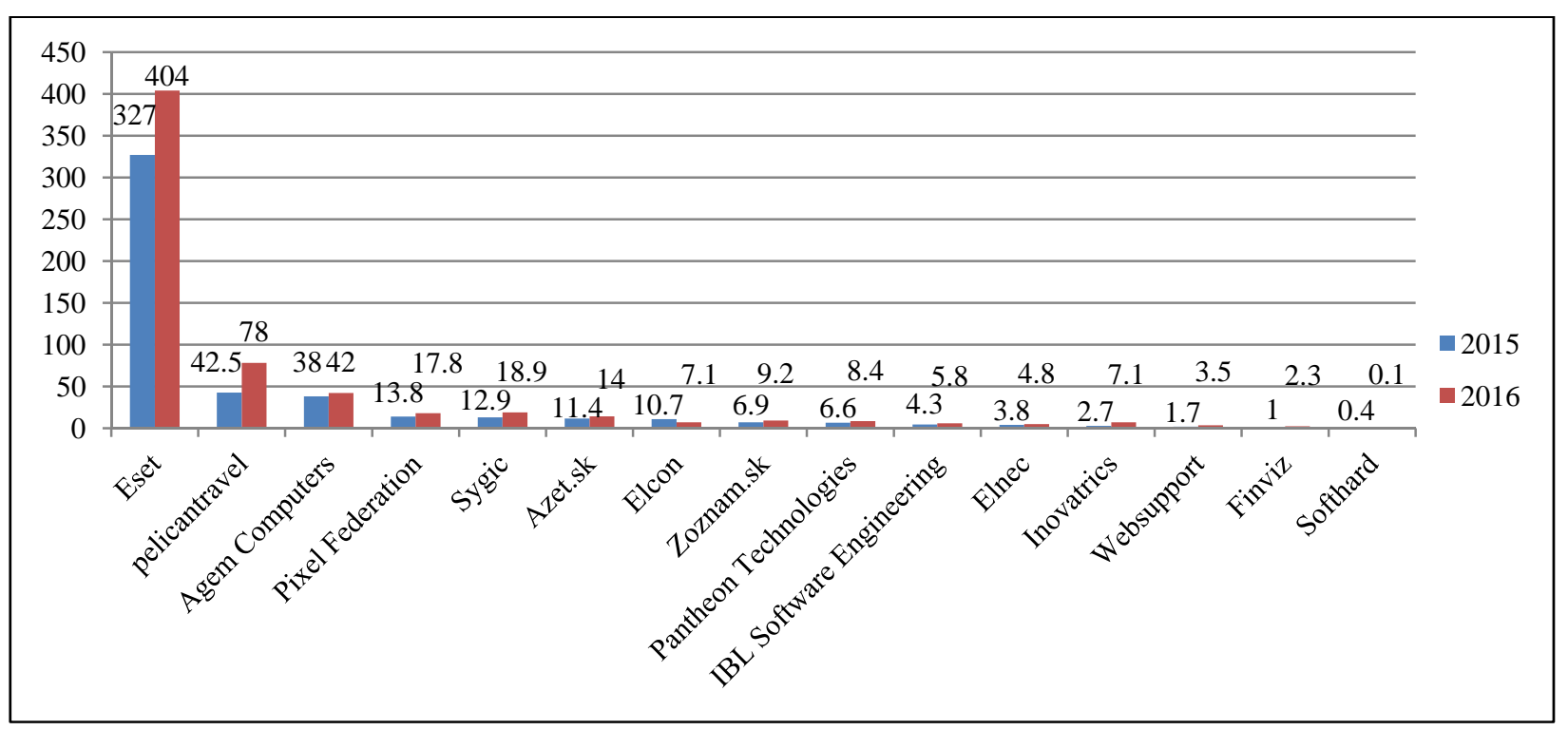

Figure 2. 15 biggest companies in Slovakia which began as startup (according revenues in mil. €). Source: Portal Finstat.

\section{Research Results of Startups}

Our survey showed that out of the 153 start-ups, 133 were established by founders with university degree, which represents an $86.9 \%$ share. Out of the 133 founders, 81 of them had a university degree in the field of IT, 
i.e., it is a 52.9\% share. Managerial and economic education was present in case of 45 founders, which represents a $29.4 \%$ share and 27 founds had a university degree in other fields. $82.4 \%$ of the founders of the approached startups were male and $17.6 \%$ were female.

To the question what resources you finance your startup from, 98 companies responded that they used their own resources (savings). It is the highest share amounting to $64.1 \%$. It is followed by financing with the help of family and friends- -17 answers, $11.1 \%$. The next place belongs to crowdfunding -12 answers, $7.8 \%$ share. It is followed by business angels with eight answers, 5.3\%. Six answers were in each of the last three groups, namely funds, banks, and others. Each group has a 3.9\% share.

The answers to the question in which stage your startup is in now, were as follows:

Table 2

\begin{tabular}{ll} 
Stage of Startup & \\
\hline Stage of stratup & Percentage \\
\hline Concept/idea & $3 \%$ \\
Prototype & $39 \%$ \\
Initial revenues & $31 \%$ \\
Growing revenues & $20 \%$ \\
Expansion to new markets & $7 \%$ \\
Maturity & $0 \%$ \\
\hline
\end{tabular}

Source: Own elaboration.

$79 \%$ of the companies responded that their priority for next year is increase of sale $68 \%$ of companies stated as priority also development of their product.

The main goal of creating a startup is to offer a product based on innovation with high added value. Statistics show that in more than $90 \%$ of cases startups fail because they do not estimate the market potential correctly, customers are not interested in their product, or the start-up does not know how to sell it.

\section{Conclusion}

Slovakia has all that is necessary for the startup ecosystem. Simpler establishment of companies was introduced in the form of the already mentioned simplified joint stock company. Start-ups may voluntarily register for VAT. Furthermore, tax licences for companies within three years as of establishment were cancelled, or the cooperation of higher education institutions and companies was improved. Despite this fact, further development of the system is important. The survey showed that there is a need to support women in business, because only $17.6 \%$ were female and activate more investors interested in investments in startups. The results shows, that up to $64 \%$ of startups use their own resources which is very expensive for them. Information should be improved not only among startup entrepreneurs but also among investors. Many investors, if they see that the startup is still non-profit, are afraid to invest in it. Startup must show growth and development, then it tends to be profitable in the future. In this sense, funding could be better developed in the form of business angels, crowdfunding, and others.

\section{References}

Blank, S. (2010). A startup is not a smaller version of large company. Retrieved 18 December 2017 from https://steveblank.com/2010/01/14/a-startup-is-not-a-smaller-version-of-a-large-company/ 
Blank, S., \& Dorf, B. (2012). The startup owner's manual: The step-by-step guide for building a great company. K\&S Ranch, Inc. ISBN 978-0-984-99930-9.

Damodaran, A. (2009). Valuing young, start-up and growth companies: Estimation issues and valuation challenges. Stern School of Business, New York University. Retrieved 18 December 2017 from http://people.stern.nyu.edu/adamodar/pdfiles/papers/younggrowth.pdf

Graham, P. (2012). Startup = Growth. Retrieved 21 November 2017 from http://paulgraham.com/gorth.html

Hošták, J. (2015). Startup support and startup ecosystem support in the Slovak Republic. Retrieved 05 December 2017 from http://www.dekys.sk/cd_apvv_lpp-038409_monitorovacia_sprava_2015/PUBLIKA\%C4\%8CN\%C3\%81\%20\%C4\%8CINN OS\%C5\%A4/KONFERENCIE/SAPRIA/ZBORNIK\%20BOBOTY\%20CD/8.\%20Prezentacie/1.\%20Juraj\%20Ho\%C5\%A1t \%C3\%A1k_\%20MH\%20SR/Juraj\%20Ho\%C5\%A1t\%C3\%A1k_\%20MH\%20SR.pdf

Klímová, V., \& Winklerová, L. (2017). Barriers to the development of innovation in the regions. In Conference Proceedings of XXth International colloquium on regional sciences (pp. 246-254). Brno: Masarykova Univerzita. ISBN 978-80-210-8586-2. doi:10.5817/CZ.MUNI.P210-8587-2017-31

Ministerstvo FinanciÍ SR. (2015). Concept for startup support and startup ecosystem in the Slovak Republic. Retrieved 12 November 2017 from www.rokovania.sk/File.aspx/Index/Mater-Dokum-189244

Ries, E. (2011). The lean star-up: How today’s entrepreneurs use continuous innovation to create radically succestul businesses. New York: Cown Business. ISBN 978-0-307-88791-7.

Startup Commons. (2017). Startup commons. Retrieved 03 December 2017 from http://www.startupcommons.org/

Thanedar, N. (2012). Are you building a small business or start-up? Retrieved 01 December 2017 from http://www.forbes.com/sites/theyec/2012/05/15

Zäch, S., \& Baldegger, U. (2017). Leadership in start-ups. International Small Business Journal: Researching Entrepreneurship, 35(2), 157-177. ISSN 02662426. 